\title{
Delayed pneumothorax after transbronchial lung biopsy
}

\author{
Stephanie Ibrahim, ${ }^{1,2}$ Maria Inez Velez, ${ }^{1,2}$ Nilam J Soni, ${ }^{1,3}$ Kevin C Proud (1) 1,2,3
}

'Department of Medicine, University of Texas Health San Antonio, San Antonio, Texas, USA

${ }^{2}$ Medical Intensive Care Unit, University Health System, San Antonio, Texas, USA

${ }^{3}$ Medicine Service, South Texas Veterans Health Care System, San Antonio, Texas, USA

\section{Correspondence to}

Dr Kevin C Proud;

proud@uthscsa.edu

Accepted 3 March 2021
Check for updates

(C) BMJ Publishing Group Limited 2021. No commercial re-use. See rights and permissions. Published by BMJ.

To cite: Ibrahim S, Velez MI, Soni NJ, et al. BMJ Case Rep 2021;14:e240985. doi:10.1136/bcr-2020240985

\section{DESCRIPTION}

A 56-year-old woman underwent a bronchoscopy with transbronchial biopsy for work up of interstitial lung disease. The procedure was uneventful and preprocedure and immediately postprocedure lung ultrasound examinations demonstrated no evidence of pneumothorax (video 1). Per hospital protocol, a postprocedure portable chest X-ray (CXR) was obtained but was delayed by 2 hours. The CXR revealed a moderate-sized left pneumothorax (figure 1). A repeat lung ultrasound demonstrated absence of lung sliding and presence of lung point confirming development of pneumothorax (video 1). The pneumothorax was successfully treated with a small-bore tube thoracostomy. The patient was discharged home the next day without further complications.

Pneumothorax complicates approximately $0.63 \%-0.97 \%$ of transbronchial biopsies based on large series conducted in the modern era, but complicates $7.2 \%$ of transbronchial biopsies in patients with interstitial lung disease. ${ }^{1-3}$

In clinical practice, many believe postprocedure pneumothoraces develop quickly (ie, within 1 hour following the procedure), but few studies have reported the time course of post-bronchoscopy pneumothoraces. ${ }^{4}$ However, many reports of delayed pneumothorax have been described. ${ }^{5-7}$ No universal definition of delayed pneumothorax exists, but it is often defined as being absent on initial postprocedure imaging but present on subsequent imaging. The time interval to develop a delayed pneumothorax varies between initial and subsequent imaging and ranges from 1 hour to approximately 5 days. ${ }^{478}$ Intervals as long as 5 months have been reported; however, in those cases

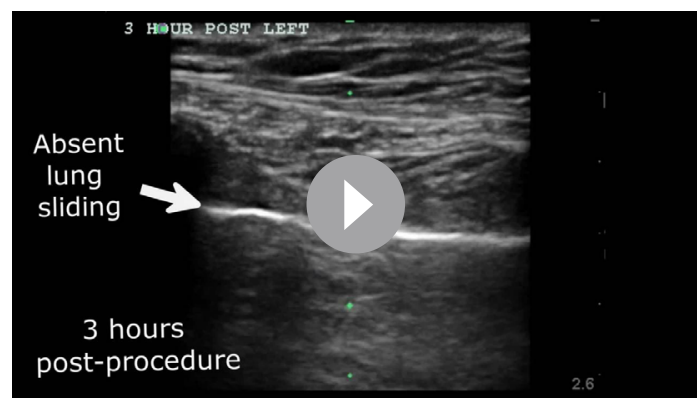

Video 1 Preprocedure and postprocedure lung ultrasound exam. Lung sliding is seen on ultrasound during the preprocedure and immediate postprocedure evaluation. The 3-hour postprocedure evaluation of the left upper lobe clearly demonstrates a moderate-sized pneumothorax.

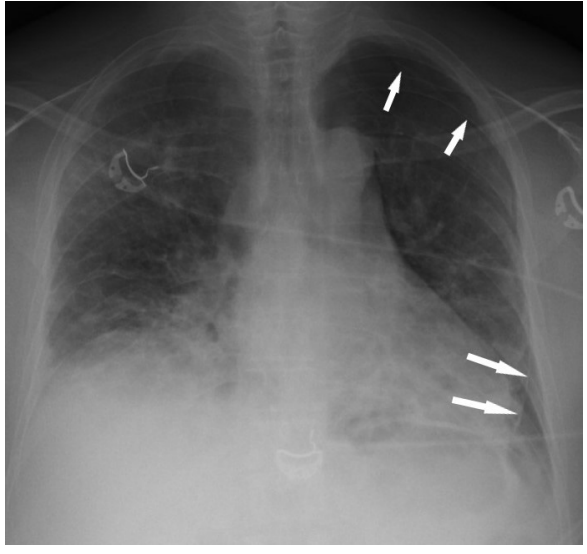

Figure 1 Postprocedure chest X-ray. A chest Xray acquired approximately 2 hours postprocedure demonstrated a moderate-sized left pneumothorax (arrows).

unrelated secondary spontaneous pneumothorax cannot be completely excluded. ${ }^{69}$

Literature on delayed pneumothorax following transbronchial biopsy is limited to case reports. ${ }^{5-7}$ In contrast, the literature on delayed pneumothorax following transthoracic needle biopsy is more robust. Approximately $20 \%$ of transthoracic needle biopsies are complicated by pneumothorax, a rate up to 20 times that of transbronchial biopsy. ${ }^{18}$ Thus, transthoracic needle biopsy cases may serve as a better model to study the timing of iatrogenic pneumothoraces due to the overall increased frequency. In such studies, $15 \%-18 \%$ of pneumothoraces that occurred were considered to be delayed. ${ }^{1011}$ Furthermore, delayed pneumothoraces are likely under-reported due to patients being asymptomatic and institutional protocols requiring only an immediate postprocedure imaging study.

Despite being relatively uncommon, a delayed pneumothorax following transbronchial biopsy can evolve into a life-threatening situation, particularly in patients travelling to remote locations, flying by plane soon after bronchoscopy or using noninvasive positive pressure ventilation at home.

CXR has been the standard modality for detecting a postprocedure pneumothorax; however, its role after transbronchial biopsy in asymptomatic patients has been questioned due to its low yield. ${ }^{12}$ In comparison, clinicians can use bedside lung ultrasound to rapidly rule out pneumothorax by detecting lung sliding, lung pulse or comet tails. A meta-analysis found higher sensitivity ( $79 \%$ vs $40 \%$ ) and similar specificity (98\% vs 99\%) of lung ultrasound compared with CXR for detection of 
pneumothorax..$^{13}$ For detection of postprocedure pneumothorax, lung ultrasound has been shown to have a sensitivity of $88 \%-100 \%$ and specificity of $97 \%-100 \% .^{14-16}$

Delayed pneumothorax is an underappreciated complication after transbronchial biopsy that may require tube thoracostomy as demonstrated by this case. Given the clear lung sliding seen on the immediate postprocedure lung ultrasound examination, we believe the pneumothorax was not missed but rather developed in the ensuing hours postprocedure. This case highlights that imaging done immediately after bronchoscopy may not be as sensitive for iatrogenic pneumothorax as imaging done 2 hours postprocedure.

\section{Learning points}

- Clinicians should be vigilant for the development of a delayed postprocedure pneumothorax that can manifest a few or several hours after transbronchial biopsy.

- Trained clinicians can perform serial lung ultrasound examinations to monitor for development of delayed postprocedure pneumothorax.

- Lung ultrasound has superior sensitivity but similar specificity as chest X-ray for detection of pneumothorax.

Contributors $\mathrm{SI}, \mathrm{KCP}, \mathrm{MIV}$ and NS contributed to the conceptualisation of the case report. SI and KCP collected patient data, and KCP, MIV and NS interpreted the data. KCP, NS, SI and MIV drafted the manuscript, made critical revisions and approved the final manuscript. KCP, NS, SI and MIV are accountable for all aspects of the manuscript and KCP is the corresponding author.

Funding NS receives funding from the US Department of Veterans Affairs, Quality Enhancement Research Initiative (QUERI) Partnered Evaluation Initiative Grant (HX002263-01A1). This material is the result of work supported with resources and the use of facilities at the South Texas Veterans Health Care System in San Antonio, Texas.

Disclaimer The contents of this publication do not represent the views of the US Department of Veterans Affairs or the United States Government.

Competing interests None declared.

Patient consent for publication Obtained.

Provenance and peer review Not commissioned; externally peer reviewed.
ORCID iD

Kevin C Proud http://orcid.org/0000-0003-3480-4069

\section{REFERENCES}

1 Tukey MH, Wiener RS. Population-Based estimates of transbronchial lung biopsy utilization and complications. Respir Med 2012;106:1559-65.

2 Asano F, Aoe M, Ohsaki Y, et al. Deaths and complications associated with respiratory endoscopy: a survey by the Japan Society for respiratory endoscopy in 2010. Respirology 2012;17:478-85.

3 Galli JA, Panetta NL, Gaeckle N, et al. Pneumothorax after transbronchial biopsy in pulmonary fibrosis: lessons from the multicenter comet trial. Lung 2017;195:537-43.

4 Ahmad M, Livingston DR, Golish JA, et al. The safety of outpatient transbronchial biopsy. Chest 1986;90:403-5.

5 Levy H, Kallenbach JM, Feldman C, et al. Delayed pneumothorax after transbronchial lung biopsy. Thorax 1986;41:647-8.

6 Narula N, Siddiqui F, Siddiqui AH, et al. Delayed pneumothorax: a potential complication of transbronchial lung biopsy. Respir Med Case Rep 2018;23:170-2.

7 Rajdev K, Herring DN, Lahan S, et al. latrogenic delayed pneumothorax after transbronchial biopsy. J Investig Med High Impact Case Rep 2020:8:232470962094763.

8 Perlmutt LM, Braun SD, Newman GE, et al. Timing of chest film follow-up after transthoracic needle aspiration. AJR Am J Roentgenol 1986;146:1049-50.

9 Kwan AC, Pipavath S, Leary PJ, et al. Delayed pneumothorax after bronchoscopy in a lung transplant patient. Respir Care 2013;58:e18-19.

10 Choi C-M, Um S-W, Yoo C-G, et al. Incidence and risk factors of delayed pneumothorax after transthoracic needle biopsy of the lung. Chest 2004;126:1516-21.

11 Byrd RP, Fields-Ossorio C, Roy TM. Delayed chest radiographs and the diagnosis of pneumothorax following CT-guided fine needle aspiration of pulmonary lesions. Respir Med 1999;93:379-81.

12 Izbicki G, Shitrit D, Yarmolovsky A, et al. Is routine chest radiography after transbronchial biopsy necessary?: a prospective study of 350 cases. Chest 2006;129:1561-4.

13 Alrajab S, Youssef AM, Akkus NI, et al. Pleural ultrasonography versus chest radiography for the diagnosis of pneumothorax: review of the literature and metaanalysis. Crit Care 2013;17:R208.

14 Kumar S, Agarwal R, Aggarwal AN, et al. Role of ultrasonography in the diagnosis and management of pneumothorax following transbronchial lung biopsy. J Bronchology Interv Pulmonol 2015;22:14-19.

15 Reissig A, Kroegel C. Accuracy of transthoracic sonography in excluding postinterventional pneumothorax and Hydropneumothorax. Comparison to chest radiography. Eur J Radiol 2005;53): :463-70.

16 Sartori S, Tombesi P, Trevisani L, et al. Accuracy of transthoracic sonography in detection of pneumothorax after sonographically guided lung biopsy: prospective comparison with chest radiography. AJR Am J Roentgenol 2007;188): :37-41.

Copyright 2021 BMJ Publishing Group. All rights reserved. For permission to reuse any of this content visit

https://www.bmj.com/company/products-services/rights-and-licensing/permissions/

BMJ Case Report Fellows may re-use this article for personal use and teaching without any further permission.

Become a Fellow of BMJ Case Reports today and you can:

- Submit as many cases as you like

- Enjoy fast sympathetic peer review and rapid publication of accepted articles

- Access all the published articles

- Re-use any of the published material for personal use and teaching without further permission

Customer Service

If you have any further queries about your subscription, please contact our customer services team on +44 (0) 2071111105 or via email at support@bmj.com.

Visit casereports.bmj.com for more articles like this and to become a Fellow 